\title{
A educação especial em Portugal. Uma memória do movimento associativo dos pais de cidadãos deficientes: as Cooperativas de Educação e Reabilitação (CERCIS)
}

\section{Special education in Portugal. Parents of handicapped citizen associative movement recollection: Cooperatives of Education and Rehabilitation (CERCIS)}

\author{
José António Afonso* \\ José António Martin Moreno Afonso**
}

\begin{abstract}
RESUMO
Em dois momentos se estrutura o texto. Um primeiro dá conta do movimento de integração na escola pública das crianças e jovens deficientes mentais. Um segundo sublinha o nascimento e consolidação de cooperativas de pais de cidadãos deficientes mentais enquanto momento fundamental na criação de uma sociedade inclusiva; nesta reflexão ainda se marca como as iniciativas dos pais se vão posicionando face às mudanças políticas que se têm sucedido no Portugal pós 25 de abril de 1974. Palavras-chave: deficiência mental, inclusão, cooperativas de pais.
\end{abstract}

Docente do Departamento de Pedagogia do Instituto de Psicologia e Educação da Universidade do Minho (Portugal).

** Sócio fundador da CerciGaia e militante da causa da integração do Cidadão Deficiente Mental e do Cooperativismo (Portugal). 


\begin{abstract}
In two moments one can structure the text: the first one informs on the moment of integration in the public school of the children and young people with mental disability; the second one emphasis the beginning and consolidation of the Cooperatives of Parents of Mentally Handicapped Citizens as a main reason for the creation of an inclusive society; in this reflexion is remarkable again as these parents' initiatives are increasing and taking new positions facing the political alterations occurred in Portugal since April 25 $5^{\text {th }}, 1974$.

Key-words: mental disability, inclusion, cooperatives of parents.
\end{abstract}

\title{
Introdução
}

Escolas especiais, ${ }^{1}$ sala de apoio permanente, sala de apoio periódico, integração total na sala de aula, são algumas das possibilidades que, de momento, se oferecem em Portugal, cada uma com as suas potencialidades e restrições. Compete aos pais e educadores decidir qual o meio que poderá oferecer melhores condições para responder, em cada momento, às necessidades educativas de cada criança ou jovem com Necessidades Educativas Especiais. ${ }^{2}$ No entanto, a inclusão de crianças e jovens em cada uma destas modalidades de educação está longe de estar operacional ou generalizada, sendo as taxas de cobertura em Educação Especial ainda relativamente baixas.

Entre os anos 70 e 80 do século XX, três dispositivos jurídicos configuram o conjunto de princípios que há bastantes anos consignavam nas convenções internacionais direitos fundamentais dos cidadãos deficientes: Constituição da República Portuguesa (1976), Lei de Bases do Sistema Educativo

1 Escolas Especiais recobrem genericamente as escolas criadas pelas associações e cooperativas de pais, que emergiram nos anos 60/70 do século XX, sem fins lucrativos e as escolas privadas com fins lucrativos que começaram a proliferar a partir dos anos 70/80 de modo acentuadamente assimétrico: $85 \%$ desses estabelecimentos situam-se na região de Lisboa.

2 O conceito de Necessidades Educativas Especiais surge em 1991 e responde à progressiva democratização da sociedade, reflectindo o postulado da filosofia da integração e proporcionando uma igualdade de direitos, nomeadamente no que concerne à não discriminação de toda a criança e adolescente em idade escolar. 
(1986) e Lei de Bases da Prevenção e da Reabilitação e Integração das Pessoas com Deficiência (1989).

As condições históricas da sociedade portuguesa convergiram para que os estádios dos direitos sociais da igualdade de oportunidades e da integração (em consonância com a tipologia proposta pela Unesco) se cruzassem num tempo demasiado recente quando comparado com os ritmos que tiveram nas diferentes formações sociais europeias (ARAÚJO, 2001). Ganham então visibilidade princípios como o da universalidade e o da solidariedade que se consubstanciam nos direitos ao desenvolvimento da personalidade, da qualidade de vida e da proibição da discriminação, que promovem a ideia de comunidade constitucional inclusiva (ARAúJo, 2001, p. 158). Assim, na Lei de Bases do Sistema Educativo ganham força os tópicos da integração e da normalização quando se prevê um ensino básico universal, obrigatório e gratuito, com a duração de 9 anos ( $\left.\operatorname{art.}^{\circ} 6-1\right)$, para todos (art. ${ }^{\circ} 18-1$ ) tendo implícita uma educação permanente (educação pré-escolar e extra-escolar) onde se valoriza a vertente formativa - a finalidade socializadora, com $50 \%$ de referências no articulado, contrapõe-se à transmissão-assimilação - e as componentes: cultura escolar, cultura quotidiana, relação escola-meio e a articulação saber teórico/saber prático. Na Lei de Bases da Reabilitação e Integração das Pessoas com Deficiência estão previstas três modalidades de reabilitação que assegurem uma individualização formativa em consonância com o tipo de handicap.

Apesar de um sistema legal concretamente constituído, ainda não estão suficientemente disseminadas, pelas escolas e pela sociedade em geral, práticas que promovam a cidadania. ${ }^{3}$ A especificidade portuguesa fez emergir quatro tipos de estabelecimento que lidam com crianças e jovens com Necessidades Educativas Especiais: cooperativas e associações de pais, colégios particulares com fins lucrativos, Instituições Particulares de Solidariedade, além dos processos de inclusão na escola regular (Ministério da Educação). No ano lectivo de 1997-1998, as escolas regulares integravam cerca de $20,4 \%$ da população que frequentava o Ensino Especial; nas escolas do Ministério do Trabalho e da Solidariedade concentravam $10 \%$ e nos outros equipamentos atendiam-se $69,6 \%$.

3 Poder-se-ão convocar duas ilustrações pertinentes de como as práticas de inclusão ainda não estão assimiladas na escola regular - sistema público de educação - (ver "Envolver quem está de fora", p. 33-34) nem disseminadas no que se refere à mobilidade e qualidade de vida (ver "Deficientes e edifícios públicos..." p. 8-13). 
O universo de alunos com NEE rondará os 250.000 com uma distribuição por dificuldade de aprendizagem (40\%), problemas de comunicação $(22 \%)$, deficiência mental (14\%), perturbações emocionais (10\%) e outros $(6 \%)$ (cf. CORREIA, 1997). Especifique-se, em termos de contextualização, o que se apurou em termos estatísticos sobre a população deficiente. Entre setembro de 1993 e junho de 1995, decorreu o Projecto "Quanti" que se baseou numa amostra significativa ao nível do distrito e dos concelhos com mais de cem mil habitantes, tendo sido recolhidos dados junto de 47.020 famílias, residentes em 73.375 alojamentos em Portugal Continental e nas Regiões Autónomas dos Açores e Madeira, num universo que abrangeu 142.112 indivíduos (PORTUGAL, 1996). O inquérito lançado partiu da noção que os próprios indivíduos inquiridos têm das alterações provocadas pela deficiência nas suas capacidades de realização. No seu comportamento e, de forma mais ampla, na sua participação social. Adoptou-se o conceito da OMS que define deficiência como qualquer perda ou alteração de uma estrutura ou de uma função psicológica, fisiológica ou anatómica, de carácter temporário ou permanente e criaram-se cinco grandes grupos de deficiência: psíquicas, sensoriais, físicas, mistas ( $v g$. plurideficiência) e nenhuma em especial.

A extrapolação (nos limites de confiança estatisticamente permitidos) dos resultados obtidos, revela um valor global de $9,16 \%$ de população com deficiência, valor muito próximo de outros países europeus.

QUADRO 1: DISTRIBUIÇÃO DAS DEFICIÊNCIAS POR TIPO E ESCALÃO ETÁRIO

\begin{tabular}{|c|c|c|c|c|c|c|}
\hline \multirow{2}{*}{$\begin{array}{l}\text { ESCALÃo } \\
\text { ETÁRIO }\end{array}$} & \multicolumn{5}{|c|}{ DEFICIÊNCIAS } & \\
\hline & Psíquicas & Sensoriais & Físicas & Mistas & Nenhuma & \\
\hline $0-2$ & 1.447 & 473 & 4.149 & 413 & 501 & \\
\hline $3-5$ & 1.026 & 1.700 & 7.881 & 649 & 134 & \\
\hline $6-15$ & 18.092 & 11.208 & 20.279 & 2.719 & 1647 & \\
\hline 16-24 & 17.680 & 10.999 & 24.177 & 2.079 & 2.408 & \\
\hline 25-34 & 19.288 & 10.785 & 34.727 & 904 & 2.575 & \\
\hline $35-44$ & 17.332 & 13.749 & 44.597 & 2.443 & 2.544 & \\
\hline $45-54$ & 15.339 & 24.001 & 72.029 & 1.694 & 1.892 & \\
\hline $55-64$ & 15.919 & 36.070 & 124.793 & 4.252 & 6.426 & \\
\hline $65-74$ & 11.018 & 49.584 & 134.647 & 3.038 & 6.829 & \\
\hline$>74$ & 10.150 & 160.533 & 104.372 & 7.160 & 17.513 & \\
\hline Total & 127.289 & 219.311 & 571.652 & 25.352 & 42.289 & 985.893 \\
\hline
\end{tabular}

FONTE: SNR (1996) 
Convém, novamente, sublinhar que os valores relativos à deficiência que foram apurados se referem à percepção dos inquiridos sobre a causa das suas incapacidades e não de uma avaliação directa. No que concerne às causas das deficiências, foram avaliadas da seguinte forma (por ordem decrescente): doença comum $(39,3 \%)$; outras origens $(15,9 \%)$, hereditariedade $(11,6 \%)$, senilidade $(7,8 \%)$, parto $(5,0 \%)$, gravidez $(4,3 \%)$, acidentes domésticos $(3,1 \%)$, doença profissional $(2,2 \%)$, outros acidentes $(2,2 \%)$ e guerra $(1,5 \%)$. De acordo com os valores apurados, as deficiências físicas representam $58 \%$, as deficiências sensoriais $22,3 \%$, as deficiências psíquicas $12,9 \%$, nenhuma em especial $4,3 \%$ e as deficiências mistas $2,5 \%$.

Uma outra questão que o inquérito pretendia identificar relacionava-se com as incapacidades na população portuguesa. Segundo a OMS, a incapacidade consiste na restrição ou falta de capacidade para realizar uma actividade dentro dos limites considerados normais para um ser humano. As incapacidades podem ser temporárias ou permanentes, reversíveis ou irreversíveis, progressivas ou regressivas e são sempre o resultado de uma deficiência. Foram apuradas as seguintes percentagens (por ordem decrescente): cegueira $(0,8 \%)$, surdez $(1,2 \%)$, fala $(4,0 \%)$, outras incapacidades de comunicação $(5,3 \%)$, tarefas diárias $(6,5 \%)$, audição $(7,0 \%)$, cuidado pessoal $(7,9 \%)$, visão $(8,2 \%)$, comportamento $(12,1 \%)$, locomoção $(21,6)$ e face a situações $(25,4 \%)$. O valor total de incapacidades detectadas é de 1.618.515, que ultrapassa o número de indivíduos com incapacidade porque se pode sofrer de mais do que uma incapacidade. No inquérito também se quis conhecer as desvantagens que, de acordo com a OMS, são: capacidade de ocupação (capacidade da pessoa para usar o seu tempo de uma forma considerada normal de acordo com o seu sexo, idade e cultura) - 591.983 (32\%); independência económica (capacidade de uma pessoa para manter uma independência económica normal, considerando o sexo, idade e cultura) - 355.707 (19\%), mobilidade (capacidade da pessoa para se deslocar no meio) - 263.021 (14,2\%); independência física (capacidade da pessoa para ter uma existência independente) - 241.047 $(13,1 \%)$; integração social (capacidade da pessoa para estabelecer e manter relações sociais) - 212.369 (11,5\%), e orientação (capacidade do sujeito para receber os sinais provenientes do meio, assimilá-los e dar-lhes resposta adequada) - $182.575(9,9 \%)$.

No art. $^{\circ} 71$ da Constituição da República Portuguesa enfatizam-se os seguintes direitos: "Os cidadãos física ou mentalmente deficientes gozam plenamente de direitos e estão sujeitos aos deveres consignados na Constituição, com ressalva do exercício ou do cumprimento daqueles para os quais se encontram incapacitados". Deste enquadramento constitucional decorrem as 
normas jurídicas que regulam a reabilitação, concebida como qualquer tipo de intervenção destinada a recuperar, em maior ou menor grau, a deficiência que afecta uma pessoa (educação especial, formação profissional, integração laboral e social, espaço e mobilidade para cegos, reeducação da linguagem, técnicas ortopédicas e cirúrgicas, etc.).

Saber qual o estado da população deficiente em termos de reabilitação foi, então, um outro objectivo do inquérito, e neste aspecto os resultados apontam para o diagnóstico seguinte: no grupo etário $0-2$ anos $33 \%$ recebe (ou recebeu) reabilitação; no grupo 3 - 5 anos os valores rondam os $28 \%$; no grupo 6 - 15 anos tem-se o valor de 41\%; no grupo 15 - 24 anos o valor situase nos 37\%; no grupo 25 - 34 anos 33\% recebe (ou recebeu) reabilitação; o grupo 55 - 64 anos tem $27 \%$; no grupo 65 - 74 anos $24 \%$ e com mais de 75 anos $17 \%$.

A partir do inquérito podemos concluir que as diferenças ainda não são reconhecidas, não se verificando a garantia constitucional da igualdade de oportunidades; as instituições continuam a excluir minorias e a integrar outras timidamente como as crianças e jovens com deficiência. Há instituições onde prevalecem métodos de estádio do assistencialismo novecentista. Prevalecem concepções de deficiência como doença e forte descoordenação de medidas e políticas dos sectores com responsabilidades na integração. Contudo, o direito à integração começa a ser um valor assumido por um número crescente de cidadãos e organizações na linha de defesa de direitos e valores fundamentais inerentes à condição humana.

\section{Estruturação da educação especial: alguns aspectos}

Convirá, ainda que de forma breve, sublinhar como se foi construindo o sistema da Educação Especial, enfatizando as particularidades dos elementos que se configuram em nível estrutural, merecendo relevância as particularidades históricas, as heranças que contemporaneamente estão incrustadas e a especificidade das organizações não governamentais.

Uma primeira reflexão prende-se ao modo como se foi consolidando a Educação Especial, destacando-se nesta trajectória a estranheza com que foi encarada, por parte dos poderes públicos, a constituição de um sector específico que promovesse as aprendizagens fundamentais de todo um conjunto de 
população com necessidades especiais, que se traduziu na importância de publicamente assumir que a educação especial se integrasse na política educativa, contrastando com a abertura intelectual relativa às problemáticas da deficiência e aos modelos teóricos que, um pouco, por todo o lado nasciam mas prestavam, também, particular atenção às respostas institucionais que iam sendo criadas. Em Portugal, contudo, as soluções tardavam, e mesmo quando surgiram estavam eivadas por uma matriz eugénica ancorada nas teorias da degenerescência - que presidiram à criação dos asilos - e nalgumas correntes da psiquiatria que banalizaram o conceito oligofrénico - que reforçaram a política de segregação. Neste contexto ganharam consistência as classes especiais e os centros de educação especial, baseados numa concepção de sectorizar as respostas por tipo de deficiência, aliás verbalizadas expressivamente, em 1934, por Eusébio Tamagnini, Ministro da Instrução, quando dividiu a população escolar portuguesa em cinco grupos: ineducáveis, normais estúpidos, com inteligência média, com inteligência superior e notáveis. A precisão do Ministro vai ao ponto de particularizar a distribuição dessa população: na primeira categoria encontrar-se-iam $8 \%$, na segunda $15 \%$, na terceira $60 \%$, na quarta $15 \%$ e na quinta $2 \%$. Em paralelo germinava o pensamento médico-pedagógico que se objectivava na especificidade de destrinçar os diagnósticos - clínico e psicopedagógico - em função das respostas institucionais, baseando os seus critérios de actuação no princípio de racionalizar integralmente os recursos humanos, ou seja, a urgência da especialização profissional e institucional. O núcleo do pensamento médico-pedagógico era o de definir a deficiência como uma patologia orgânica, correlacionandose explicitamente deficiência mental com um estatuto sócio-económico precário, logo a opção por internatos - onde se controlariam os efeitos perversos do meio social de origem dos deficientes - surgiu com grande força. Por volta dos anos 50-60 do século XX, começam a ganhar consistência as críticas oriundas de sectores da Pedagogia e da Psicologia que, na continuidade dos desenvolvimentos da Psicologia da Criança e de algumas intuições de Freud - particularmente quando sublinha a existência de perturbações relacionais como factor inibidor de aprendizagem -, vieram colocar em causa a lógica do internato e das classes especiais, enfatizando que os espaços fechados são potencialmente restritivos para a aprendizagem e que, também, esta não se consegue plenamente quando não há contactos com o exterior.

Para este aspecto contribuíram, quer educadores, quer os pais, quando começaram a questionar em que moldes se processaria a transição para a vida normal. Os pais, nessa época, demonstravam que eram imprescindíveis para a configuração dos espaços com lógicas distintas daquelas que estavam 
estabelecidas para os centros de origem estatal ou para os centros de origem particular, mas apoiados pelo Estado. ${ }^{4}$

Nasciam, nos anos 60, os primeiros centros criados pelos pais dos deficientes mentais. Entre os anos 60 e 80 é consagrado, pela Europa, em Lei, o princípio da Integração - o direito de todas as crianças frequentarem uma escola normal, beneficiando-se de todas as modificações organizacionais e curriculares que a sua deficiência exige. Uma perspectiva psicossocial enforma esta nova configuração, ou seja, a integração pressupõe partilha e responsabilização. ${ }^{5}$ Em meados dos anos 70, existiam em Portugal cerca de 200 instituições para deficientes: 74 de iniciativa privada e 124 de iniciativa estatal. No conjunto, estavam concentradas em Lisboa e no Porto, com cerca de 40 tipos de estabelecimentos, e no Litoral com uma variação entre 8 e 20 estabelecimentos, o que contrastava com o interior, com menos de 8 ofertas institucionais. Observa-se, ainda, que as ofertas configuravam rupturas, ora pelo surgimento de novos protagonistas - os pais -, ora pelo alargamento da rede relativamente aos anos anteriores.

Esta evolução das respostas institucionais (mas, também, organizacionais) é acompanhada por problemáticas novas que se reflectem no uso de metodologias específicas e inovadoras (Cf. RODRIGUES, 1991).

Um balanço efectuado nos anos 90 apontava que apesar do Ensino Especial ter crescido significativamente a partir de finais dos anos 70, continuavam a existir lacunas que era urgente colmatar (GRILO, 1994), indicando-se que a taxa de cobertura da população deficiente com menos de 19 anos de idade era apenas de $28 \%$ e vincando que as exigências desse subsector do sistema educativo exigiam a formação de docentes e técnicos especializados, mas enfatizava, ainda, que era necessário desenvolver uma acção efectiva (e personalizada) que fosse ao encontro dos "problemas e dos dramas vividos por muitos jovens e por muitas famílias" (COSTA et al., 1996, p. 131-174). ${ }^{6}$

4 Para um aprofundar das questões relativas à trajectória da estruturação da Educação Especial ver Afonso (1997), Rodrigues (1999).

5 Relativamente à recepção no ordenamento jurídico do modelo social (ARAÚJO, 2001, p. 120-145).

6 Quanto à generalização da integração escolar, veja-se Pereira (1996); no que se refere ao modo como se foi consolidando um modelo de formação de professores para o Ensino Especial, com as suas virtualidades mas, também, os seus limites, Sanches (1995). Relativamente à face do vivido quotidianamente como drama e incerteza por famílias de deficientes mentais, leiam-se os relatos em Costa et al. (1996); no que se refere à dimensão da inclusão escolar ainda se verificam muitas resistências por parte dos profissionais da educação, seja por formação, seja por rigidez de adaptação da estrutura escolar aos "novos públicos", seja, ainda, por questões que se prendem às 
Sublinhe-se que no âmbito da Educação Especial, nos anos 70, confluíram as estruturas directamente vinculadas ao Estado e as nascidas da acção directa dos pais de cidadãos deficientes mentais que ocupam uma posição importante em termos das respostas e possibilidades de integração que oferecem; note-se que uma avaliação realizada em 1985 (CostA et al., 1985) com 115 instituições que desenvolviam actividades de preparação pré-profissional, mostrou que cerca de $80 \%$ eram instituições privadas sem fins lucrativos, sendo Cooperativas e Associações de pais.

\section{As Cercis: notas sobre a sua constituição e desenvolvimento}

Nos últimos decénios houve a preocupação de estabelecer um conjunto de medidas que possibilitassem uma efectiva integração; as disposições concentram-se sobretudo em dois momentos cruciais: a educação e a formação profissional.

Apesar de ambiguidades diversas que vão desde imprecisões contidas nos próprios dilemas legislativos até oposições e resistências de muitos agentes que estão inseridos como profissionais nas instituições, passando pela intensidade com que coexistem os estádios dos direitos fundamentais e da igualdade de oportunidades, verifica-se que muito do que tem sido realizado no âmbito de projectos de integração não foi previsto em diplomas e que muito do que está estipulado ainda não foi cumprido; por ainda persistirem incertezas que um grande número de deficientes não tem acesso a escolas regulares e mesmo a escolas especiais. Pelos dados disponíveis, pode-se decifrar que, apesar das preocupações manifestas pelo Ministério da Educação e pelo Ministério do Trabalho e da Solidariedade e pelo empenho em generalizar e universalizar serviço, ainda persistem lacunas da função social do Estado de bem-estar que encontram eco no modo como se processa o alargamento das políticas sociais nos (e para os) grupos sociais mais vulnerabilizados $-\mathrm{e}$ em visível processo de exclusão - (ALMEIDA et al., 1992) que tem sido lento, titubeante e marcado pela persistência de obstáculos e constrangimentos estrutu-

representações que ainda permanecem sobre a deficiência, Lopes (1997), Vaz (1995), veja-se, também, Rogério Cação, "Paradigmas e paradoxos de um processo em construção" na Revista Fenacerci (1998, p. 12-13). 
rais, mas também regionais, como ainda pela persistência da descoordenação entre as duas instâncias da tutela que está patente na valorização e uma via de integração mais administrativa do que organizacional e educacional ou reforçando a componente de formação profissional em termos exclusivamente técnicos.

Sublinhe-se, contudo, que a ruptura com práticas segregacionistas tem marcado os últimos anos ${ }^{7}$, bem como a emergência de inúmeros e novos actores, assim como o protagonismo que associações e cooperativas de deficientes assumem na consecução das políticas públicas.

Fundamentalmente a partir dos anos 80 vão ganhando consistência a criação de centros implementados e geridos pelo Estado (Centros de Gestão Directa) ou geridos em parceria em Organizações Não Governamentais (Centro de Gestão Participada), representando estes mais de $70 \%$ das ofertas. Correspondendo, em parte, a mudanças legislativas nas organizações de pais surgem áreas que completam as respostas já consolidadas: assim à vertente educativa juntaram-se a formação profissional e a integração social, com o surgimento dos Enclaves, dos Centros de Emprego Protegido, dos Centros de Actividades Ocupacionais, dos Centros de Apoio Domiciliário, bem como as Unidades Residenciais e a Intervenção Precoce.

Em 2002, quarenta e nove cooperativas de pais estão em pleno funcionamento e três encontram-se parcialmente inactivas (ver Anexo), notando-se que, em termos de organizações de pais de deficientes mentais, o projecto organizacional cooperativo está presente com alguma consistência no subsistema da Educação Especial, e que se verifica uma partilha, em termos de respostas, com associações de pais, onde se destacam as APPACDM (Associação Portuguesa de Pais e Amigos do Cidadão Deficiente Mental) que irromperam nos anos 60, num período em que eram flagrantes a quase ausência de estruturas estatais que solucionassem a problemática das crianças e jovens deficientes (APPACDM, 1998).

Após o 25 de Abril de 1974 começam a germinar as Cercis (Cooperativas para a Educação e Reabilitação de Crianças Inadaptadas). Em ambos os casos é nuclear a iniciativa dos pais de crianças com necessidades educativas especiais.

7 Para uma visão sobre um conjunto de práticas pedagógicas inovadoras que se prendem com uma sólida colaboração entre escolas regulares e cooperativas consultem-se Costa et al. (1996) e Pereira et al. (1996); no que se refere à construção de itinerários personalizados na formação profissional, Freitas et al. (1994). 
As Cercis surgem como conceito inovador com base na confiança e na esperança de um trabalho futuro, a desenvolver entre as pessoas portadoras de deficiência mental, suas famílias e os técnicos especializados. ${ }^{8}$ Procuraram, desde o primeiro momento, promover condições que privilegiassem a liberdade de escolha do projecto de vida pessoal - por parte dos próprios deficientes e suas famílias - e a sua integração nas comunidades, condições que pressupõem a existência de estruturas de suporte e de acompanhamento, assim como a presença de recursos técnicos diversificados, qualificados e com forte adequação aos níveis socioculturais das famílias.

As Cercis que de Norte a Sul polvilham o país tiveram como anos áureos de criação os de 1976,1977 e 1980. Entre 1975 e 1980 fundaram-se 70\% das cooperativas, de 1981 a 1985 criaram-se $22 \%$ e a partir de 1989 o movimento desceu para $8 \%$. Atendem cerca de 5.000 deficientes e criaram cerca de 2.300 postos de trabalho; do universo das cooperativas, $98 \%$ têm centros de Educação Especial, 76\% têm centros de Formação Profissional, 58\%, Actividades Ocupacionais, 20\% Intervenção Precoce, 18\% Residência Lar, 10\% Emprego Protegido, 4\% Enclave, 4\% Apoio Domiciliário e 4\% Jardimde-infância. As actividades cooperativas têm uma implantação concelhia, mas observa-se que as Cercis têm uma maior densidade nos distritos do litoral.

A fórmula organizativa ensaiada, o cooperativismo, terá marcado a diferença ao enfatizar a real participação de todos os implicados nos processos de integração, além de manterem, ainda hoje, um conjunto de valores como estruturantes das práticas pedagógicas: solidariedade, democracia, responsabilidade partilhada - ou seja: igualdade de direitos e deveres - progresso económico e social, que ganha expressão na reivindicação de uma melhor qualidade de vida, na intercooperação com entidades públicas e privadas, como forma de uma forte identificação comunitária, e na afirmação intransigente da persecução de fins não lucrativos. Os projectos representam, por isso, um

8 Uma memória interessante sobre o processo de construção de uma Cerci é-nos transmitida num registro romanesco, por Manuel Rodrigues (2001). Interveniente directo nos idos anos de 1974, dá-nos uma reconstrução de todos os passos dados numa comunidade rural para contrariarem o destino das crianças "aleijadinhas" e "tolinhas" que não tinham lugar na escola e que durante anos vagueavam, sem qualquer expectativa de futuro, pela aldeia. Especialmente do Capítulo IX ao Capítulo XIII, os pormenores da consolidação da associação Arco Íris (nome fictício que Manuel Rodrigues atribuiu à cooperativa) são-nos transmitidos com vivacidade e com o detalhe de quem viveu com intensidade e paixão os anos decisivos dessa associação, desde os primeiros momentos em que desmontando concepções, representações e práticas de ocultação e marginalização se procedeu ao "levantamento no nosso concelho de pessoas com problemas" (p.107) até à organização e preparação de um cortejo e baile de Carnaval que comemorava o $5^{\circ}$ aniversário. 
processo contínuo de respostas, balizadas em quatro marcos estruturantes: i) arranque das Escolas Especiais, 1975-1977; ii) programas de préprofissionalização, 1978; iii) formação profissional, 1986; iv) integração da pessoa com deficiência mental por meio da criação de novas estruturas que permitam (e prevejam) o acompanhamento global dos deficientes, bem como o apoio às suas famílias, a partir dos anos 90 . Durante anos foram inventariados problemas a que se pretendeu responder, sendo de destacar pela sua crucialidade a intervenção precoce, o paulatino envelhecimento das populações atendidas e das suas famílias (com as imprevisíveis consequências das experiências do luto e da ausência) e a qualificação profissional dos jovens. As Cercis mantiveram a preocupação de englobar um leque diversificado de respostas em sintonia com os contextos específicos de inserção geográfica e na incessante procura de soluções destaca-se a configuração de áreas educacionais que permitam uma inserção no mundo normal de trabalho ou/e, no âmbito da própria instituição, criam-se núcleos produtivos onde os deficientes, acompanhados por monitores especializados, irão produzir (como em qualquer oficina) para o mercado, surgindo, deste modo, os Centros de Emprego Protegido e os Enclave. ${ }^{9}$

As experiências de formação profissional são presentemente objecto de reflexão metodológica que permita criar dispositivos que contribuam quer para clarificar o processo de encaminhamento, quer para a adequada caracterização dos postos de trabalho susceptíveis de ser ocupados por jovens deficientes e quer, ainda, pilotar os percursos e práticas pedagógicas. A formação profissional originou projectos comuns entre várias instituições como forma de proporcionar aos jovens deficientes uma resposta integrada de formação e emprego utilizando recursos comunitários existentes nas regiões, com especial relevo para as empresas, possibilitando-se uma correcta inserção no mercado de trabalho (RABANAL; PAIVA, 1995).

As dinâmicas das Cercis tentam evitar a cristalização (e enquadram-se nos seus princípios constituintes de educar, formar e integrar), cerceiam o estancamento e estrangulamento institucionais; mas muitas destas dinâmicas dependem do relacionamento com os ministérios porque muitas das opções das cooperativas estão fortemente correlacionadas com as políticas para o sector que de forma alguma são independentes das decisões em nível global

9 Alguns relatos sobre a constituição das Cercis fornecidos pelos protagonistas estão contidos em Afonso (1997) e Veiga (1999). Sobre os projectos das Cercis e testemunhos das actividades desenvolvidas há cerca de 26 anos, podem-se encontrar informações úteis em Revista Fenacerci (1998 e 2002. p. 36-51; 54-77); veja-se, ainda, Martins (2002). 
da sociedade. ${ }^{10}$ Assim, se as Cercis não pretendem ocultar nenhuma situação vulnerável e investem nas aberturas necessárias, há, contudo, níveis de constrangimentos que afectam a autonomia organizacional: destacamento de professores, falta de pessoal especializado, precariedade económica, apoio para estruturas de pré-profissionalização, necessidade de estabelecer acordos com as tutelas que apesar de estarem regulamentados têm sido arbitrariamente geridos, apoio dos jovens deficientes (severos e profundos) não integrados na escola regular e/ou com idade superior a 18 anos; as próprias Cercis hierarquizam as dificuldades: $56 \%$ dizem que o problema mais grave é a insuficiência dos apoios ministeriais (que são amplificadas pelos atrasos das transferências de fundos, de acordo com $28 \%$ das cooperativas); para 19,4\% das Cercis uma questão ponderosa relaciona-se com a inserção profissional dos deficientes; a situação precária das instalações preocupa 13,9\% e a falta de colaboração dos pais/falta de colaboração da comunidade é avaliada por $5,6 \%$ como um problema premente; estes constrangimentos ganham mais acutilância se atendermos a que a maioria das áreas das Cercis são a educacional e a de formação profissional, bem como $74 \%$ dos alunos têm menos de 18 anos e $26 \%$ mais.

\section{A integração: que limites?}

Estes elementos permitiram balizar o quadro legal - e sociológico - em que nasceram e se foram desenvolver as Cercis, ou seja, as heranças (e as inovações) que se embeberam nestas organizações. Se, por um lado, são elementos estruturantes da sua manutenção, por outro, representam uma forte fonte de instabilidade já que tendencialmente as podem coarctar de um objectivo fundamental: promover a dignificação do cidadão deficiente mental. ${ }^{11}$ Evidenciamos que uma das características dos movimentos associativos foi uma ruptura introduzida nas práticas institucionais. Em que consistiu tal efeito? Destacaremos: i) a cooperação entre pais e técnicos com vista a insti-

${ }^{10}$ Cf. Fenacerci (1993a, 1993b, 1993c) Note-se que o desenvolvimento da formação social portuguesa após1974 vai evidenciando cada vez mais nitidamente as contradições subjacentes ao processo de modernização.

${ }^{11}$ Sobre os ciclos de vida das Cercis consulte-se Veiga (1999, p. 24-53 e 165-177). 
tuírem movimentos contra a segregação; ii) a criação de organizações em que se investiu fortemente num outro entendimento da educação especial: não encerrar o deficiente no circuito de uma instituição isolada do mundo exterior. Estes dois pontos vão-nos introduzir numa nota final que desejamos destacar; ela tem origem na identificação dos constrangimentos que se vão impondo às associações de deficientes (em particular a partir dos anos 80), mas tal não deixa, apesar de tudo, de possibilitar que alguns indícios surjam do modo em que a educação especial possa vir a ser reestruturada, tendo em atenção as organizações que contribuíram (e contribuem) para que a marginalização não seja reiterada e reificada.

É de sublinhar, em primeiro lugar, que a inovação introduzida vai-se disseminar no nível dos agentes envolvidos no processo educativo, das organizações pelas fórmulas participativas implementadas e no nível das relações entre práticas pedagógicas e comunidades, que objectivam por este meio, o sentido da mudança: criar laços capazes de impulsionar a integração. Em segundo lugar, a inovação assenta na perspectiva de que a família do deficiente é um elemento fundamental para o processo formativo (SOUSA, 1998) e que a implicação dos agentes educativos é essencial para que o processo tenha sucesso. Deste modo, a questão educativa não se pode encerrar na instituição e esta, pelo contrário, tem que ser mais um dos elementos no percurso da vida do deficiente; a instituição, por isso, tem que estar inserida no espaço e manter contactos permanentes com todos os agentes da comunidade. Os agentes desse diálogo são os profissionais que trabalham nas organizações além dos próprios pais.

Estes dois aspectos, relacionados, também com a pluralidade educacional que muitas organizações criaram marcam uma dinâmica; no entanto, as organizações manifestam sensibilidades particulares, bem como os relacionamentos entre os agentes que as integram são diferentes, configurando-se uma diversidade de situações que podem fomentar mudanças - ou, pelo contrário, encetar processos de retraimento com imprevisíveis conseqüências. Uma dimensão em que a mudança é crucial será a criação de contextos igualitários capazes de promover a negociação e a integração de modo que muitas resistências (que quotidianamente ganham sentidos) sejam desconstruídas; tais como o medo que muitos pais verbalizam quando colocam os filhos em meios que consideram menos protegidos e não preparados para os receber, tais como a recusa de muitos professores em compreender as diferenças, tais como a urgência em planificar, em nível local, a gestão de recursos que contribua para que se racionalizem as ofertas de Educação Especial e em especial que colaborem com a escola regular, tais como as concepções educativas, em 
que ainda persistem muitos responsáveis pela educação especial, que se aproxima perigosamente de modelos médicos eivados de xenofobia.

A generosidade de militar por um ideal de integração do deficiente não é por si o garante da construção de espaços não segregativos, nem o Estado é em si a possibilidade de (re)forçar a democracia; pelo contrário, há duplicidades que são perigosas: a forte probabilidade de retraimento das organizações que se cruza com normalização que o Estado reitera pelos critérios contabilísticos e a uniformidade simbólica. Nesta dimensão, a autonomia reorganizacional está ameaçada, configurando-se vias de passividade e adaptabilidade à lógica economicista e conformista de uma integração meramente formal sem qualquer expressão quotidiana - e neste aspecto a retracção das políticas sociais indelevelmente é um sintoma de não integração -, ou dito de outro modo: a não efectivação de uma comunidade constitucional inclusiva.

\section{REFERÊNCIAS}

AFONSO, J. A. O ensino especial: pais, deficientes e organizações. Vila Nova de Gaia: Estratégias Criativas, 1997.

ALMEIDA, J. F. de. et al. A exclusão social: factores e tipos. Oeiras: Celta, 1992.

APPACDM. Para uma história a fazer... 15 anos de percurso de uma sigla. Braga: APPACDM, 1998.

ARAÚJO, A. Cidadãos portadores de deficiência: o seu lugar na Constituição da República. Coimbra: Coimbra, 2001.

BAPTISTA, J.; KOVACS, I.; ANTUNES, C. L. Uma gestão alternativa: para uma sociologia da participação nas organizações, a partir de uma experiência portuguesa. Lisboa: Relógio d'Água, 1985.

CORREIA, L. de M. Alunos com necessidades educativas especiais nas classes regulares. Porto: Porto, 1997.

COSTA, A. M. B. da. et al. Currículos funcionais. Lisboa: Instituto de Inovação Educacional, 1996. $2 \mathrm{v}$.

. Transição para a vida activa dos jovens deficientes. Lisboa: SNR, 1985.

ENVOLVER quem está de fora, Revista Público, p. 33-34. jul. 1998.

FENACERCI. Cercis. Balanço e perspectivas: caracterização das necessidades de apoio das diferentes tutelas. Lisboa: Fenacerci, 1993a. 
. Deficiente mental e familia: estruturas de apoio na Europa social. Lisboa: Fenacerci, $1993 b$. . Escolas de educação especial: que futuro? Lisboa: Fenacerci, 1993c.

FERNANDES, M. M. Incentivos ao emprego de pessoas com deficiência. Portugal: Helioscope, 1994. p. 15. v. 2.

FREITAS, A. et al. Avaliação e orientação profissional: uma metodologia. Porto: CEFPI, 1994.

GRILO, E. M. O sistema educativo. In: REIS, António. (Org.). Portugal: 20 anos de democracia. Lisboa: Círculo de Leitores, 1994. p. 406-435.

LOPES, A.; RETO, L. Cooperativismo e sindicalismo: a experiência das cooperativas de produção. Lisboa: INSCOOP, 1992.

LOPES, M. C. A educação especial em Portugal. Braga: APPACDM, 1997.

MARTINS, M. Cercizimbra -26 anos de actividade. Acompanhar o projecto de vida dos deficientes mentais. Educação e Ensino, v. 26, p. 13-15, 2002.

OLIVEIRA, C. C.; ANTUNES, C. Carrington da Costa: ciência e reforma escolar. Forma, v. 20, p. 5-31, 1996.

PAIVA, F. Cerci's: Cooperativas de Solidariedade Social. In: BARROS, C. P.; SANTOS, J. C. G. dos. (Orgs.). As instituições não lucrativas e a acção social em Portugal. Lisboa: Vulgata, 1998. p.139-157.

PEREIRA, M. do C. et al. Uma perspectiva de organização curricular para a deficiência mental. Lisboa: F. C. Gulbenkian, 1996.

PORTUGAL. Secretariado Nacional para a Reabilitação e Integração das Pessoas com Deficiência. Inquérito nacional às incapacidades, deficiências e desvantagens. Reabilitação. Síntese dos resultados globais. Lisboa: SNRIPD, 1996.

RABANAL, E. ; PAIVA, I. Novas perspectivas para a integração profissional de pessoas deficientes no mercado aberto: o emprego apoiado. In: COSTA, A. et al. (Orgs.). Seminário: comunicar, informar, reabilitar. Lisboa: IEFP/SNR, 1995. p. 133-138.

REVISTA FENACERCI. Lisboa: Fenacerci, maio 2002.

REVISTA FENACERCI. Lisboa: Fenacerci, maio 1998.

RODRIGUES, D. Percursos da educação especial em Portugal: uma meta-análise qualitativa de artigos publicados em revistas não-especializadas desde 1940. Ciências da Educação em Portugal. Porto: Sociedade Portuguesa de Ciências da Educação, 1991. p. 75-89.

RODRIGUES, M. Disseste o meu nome? Lisboa: Escritor, 2001. 
. Pelo direito à cidade: o movimento dos moradores do Porto (1974/1976). Porto: Campo das Letras, 1999.

RODRIGUES, P. Crianças e alunos com necessidades educativas especiais: Parecer n. 3/99 do Conselho Nacional de Educação. Diário da República - II, Série n. 40, p. 2378-2385, 17 fev. 1999.

SANCHES, I. R. Professores de educação especial: da formação às práticas educativas. Porto: Porto, 1995.

SILVA, M. C. da. Acção sindical - transformação e desenvolvimento. Porto: Campo das Letras, 2000.

SOUSA, L. Crianças (con)fundidas entre a escola e a família. Porto: Porto, 1998.

VÁRIOS. Deficientes e edifícios públicos. Um milhão de portugueses ignorados, Revista Proteste, n. 232, p. 8-13. 2003.

VAZ, M. da C. O professor de apoio de educação especial. Coimbra: Fora do Texto, 1995.

VEIGA, C. V. Cooperativas de Educação e Reabilitação de Crianças Inadaptadas: uma visão global. Lisboa: SNR, 1999.

Texto recebido em 16 out. 2004 Texto aprovado em 19 dez. 2004 
DISTRIBUIÇÃO DAS COOPERATIVAS DE ENSINO ESPECIAL E INTEGRAÇÃO (CERCI E NÃO CERCI) EM 2002

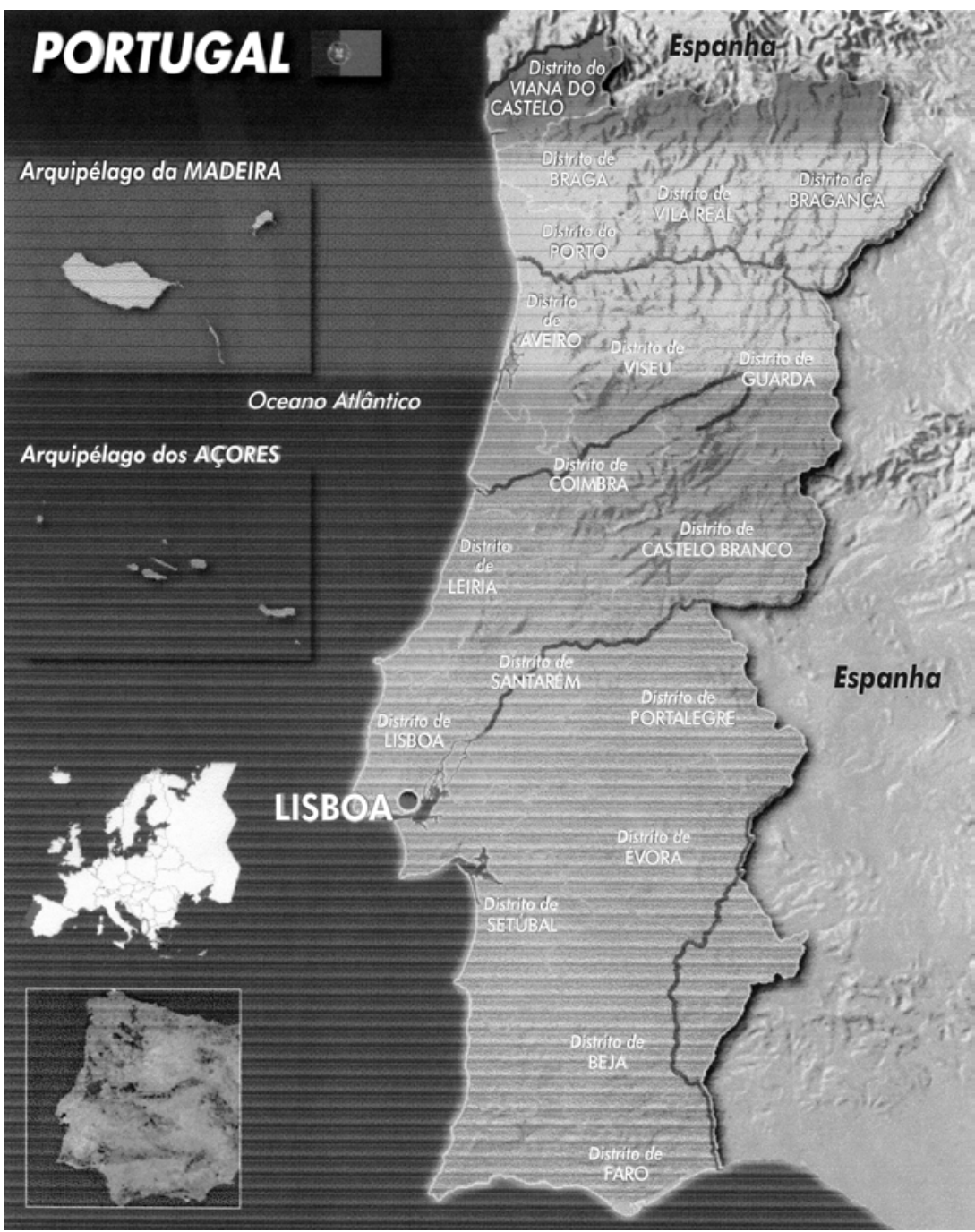

DISTRITOS COM COOPERATIVAS: AVEIRO - 9; COIMBRA - 4; LEIRIA - 5; LISBOA -10; SETÚBAL -6; BEJA - 3 ; ÉVORA - 3; FARO - 1 ; PORTALEGRE -1; BRAGA -2; PORTO -7; GUARDA - 1 .

DISTRITOS SEM COOPERATIVAS : BRAGANÇA; CASTELO BRANCO; SANTARÉM; VIANA DO CASTELO; VILA REAL; VISEU; AÇORES; MADEIRA. 